\title{
DE VIAJES INTERESTELARES Y CIVILIZACIONES ALIENÍGENAS. LA ARQUEOLOGÍA COMO ENLACE A MUNDOS DE CIENCIA FICCIÓN EN EL CINE
}

\author{
Tono Vizcaíno Estevan \\ Arqueólogo y gestor del patrimonio
}

\begin{abstract}
Resumen: La industria del cine ha encontrado en la arqueología un recurso efectivo para evocar ideas de aventura, misterio y viajes hacia el pasado. Sin embargo, existen una serie de películas del género de la ciencia ficción en las que la arqueología cambia la perspectiva y funciona como enlace a realidades paralelas de inspiración futurista, en las que hacen acto de presencia civilizaciones alienígenas y viajes interestelares. En este texto analizaremos algunos ejemplos con el propósito de conocer cuál es la percepción de la arqueología y qué aporta, desde el punto de vista narrativo, al género de la ciencia ficción.
\end{abstract}

Palabras clave: arqueología, ciencia ficción, cine, alienígena.

\begin{abstract}
About Interstellar travel and alien civilizations. Archeology as a link to science fiction worlds in the film industry
\end{abstract}

Abstract: The film industry has found in archaeology an effective way to evoke ideas of adventure, mystery and time travel. However, there are some science fiction films in which archaeology changes the perspective and works as a link to parallel realities of futuristic inspiration, in which alien civilizations and interstellar travels make an appearance. In this text we will analyse some of these examples with the purpose of knowing the perception of archaeology and identifying its contribution to the narratives of science fiction.

Key words: archaeology, science fiction, film, alien.

\section{INTRODUCCIÓN: ARQUEOLOGÍA Y CULTURA DE MASAS}

En el imaginario occidental contemporáneo, la arqueología aparece indisolublemente ligada a las civilizaciones antiguas. La atracción que siguen despertando los restos materiales del pasado, así como la percepción de la arqueología como la disciplina por antonomasia encargada de su recuperación y estudio, la han convertido en un referente habitual de la cultura de masas (casi) siempre que el pasado hace acto de presencia (Hall, 2004; Holtorf, 2005, 2007; Ruiz Zapatero, 2012; Vizcaíno Estevan, 2013).

Data de recepció: 20 de maig de 2019 / Data d'acceptació: 31 de juliol de 2019. 
Si bien se trata de un referente poco homogéneo en cuanto a representación, pues los estereotipos en torno a la figura del arqueólogo son dispares e incluso la definición misma de la profesión ofrece lecturas divergentes (Holtorf, 2007: $62 \mathrm{ss}$ ), existen una serie de patrones comunes que han contribuido a asentar una imagen compartida, con frecuencia alejada de la realidad de la profesión. De entre ellos conviene resaltar tres.

En primer lugar, la arqueología es presentada como una actividad que fetichiza la cultura material del pasado frente al conocimiento de las sociedades que le dieron sentido. Utilizamos aquí expresamente el concepto de «actividad», pues la arqueología no siempre se representa como una verdadera profesión, sino muy a menudo como un auténtico hobby, más próximo a la actividad ilícita del expolio y el tráfico de antigüedades que a la práctica científica. En este planteamiento pesa mucho la herencia decimonónica, que entendía la arqueología como la forma más distinguida de coleccionismo de antigüedades (Mora, 2015; Rodríguez Temiño, 2015). Efectivamente, en un momento en que existían instituciones relacionadas con la recuperación del pasado -por ejemplo los museos arqueológicos- pero no una verdadera profesionalización, la arqueología no era sino una afición de eclesiásticos y burgueses con un cierto interés por la historia y, sobre todo, por su materialidad, sobre la cual se proyectaba un goce intelectual, estético e identitario (Burch, 2007).

En segundo lugar, y en directa relación con lo anterior, a la arqueología se le dota en la cultura de masas de un cierto componente de aventura que bebe directamente de las expediciones coloniales de los siglos XIX y XX. La institucionalización de la arqueología en Europa en el siglo XIX, a través de la creación de museos arqueológicos nacionales y de otros organismos encargados de la recuperación de antigüedades, fue una más de las consecuencias de los procesos de construcción nacional (Díaz-Andreu, 1995). Algunos de los estados-nación buscaron legitimar a través del pasado no solamente su propia historia nacional, sino también justificar sus políticas expansionistas y colonialistas sobre otros territorios. No es casual, en este sentido, que naciones como Francia, Inglaterra, Italia o Alemania impulsasen expediciones arqueológicas en los territorios colonizados, en especial si tenían evidencias monumentales de un pasado glorioso, pues era una manera más de apropiarse de las colonias y de su cultura (Fernández Martínez, 2011).

Sin embargo, el componente de aventura asociada a la arqueología en la cultura de masas no se debe en exclusiva a la pervivencia casi icónica de las expediciones coloniales, sino también a la centralidad que tiene el trabajo de campo en la percepción de esta profesión. Dado que es común considerar que la excavación arqueológica no solo es la más importante de las tareas del arqueólogo, sino que, todavía más, se presupone que sin ella no hay arqueología, 
se acaba construyendo una asociación directa entre la arqueología y el exterior, pues realizar el trabajo al aire libre supone un distanciamiento físico y simbólico respecto de lo mundano y lo rutinario.

El tercero de los patrones compartidos en la representación de la arqueología en la cultura de masas es su uso como excusa para proyectar pasados utópicos. El pasado actúa como una válvula de escape para huir, aunque sea momentáneamente, de un presente a menudo percibido en clave negativa (Holtorf, 2005). Lo cierto es que el pasado es una construcción cultural que admite ser moldeada conforme a los anhelos del presente, y en la cultura de masas -y también en la profesión- la arqueología permite legitimar todo tipo de lecturas; incluidas las más imaginativas, en especial a la hora de relatar los pasados más remotos, pues la falta de certezas da pie a desencorsetar las interpretaciones.

En la conformación de esos imaginarios sobre la arqueología ha tenido mucho que ver la popularización en los medios de comunicación de una serie de referentes que coquetean, con mayor o menor fortuna, con el trabajo arqueológico. Desde ídolos de masas como Indiana Jones y Lara Croft, pasando por personajes menores como los de series y películas del tipo Cazatesoros, La Búsqueda o La Momia, hasta llegar, incluso, a los profesionales que aparecen en algunos documentales, los arqueólogos son percibidos como adalides de las reliquias antiguas y mediadores del contacto presente-pasado (Hall, 2004; Vizcaíno Estevan, 2013, 2014). Un contacto que en ocasiones se manifiesta de manera puramente simbólica, esto es, a través del desciframiento de códigos secretos y de la producción de nuevos conocimientos sobre el pasado; pero más habitualmente mediante viajes en el tiempo que pueden darse en una doble dirección: o bien protagonistas del presente que viajan al pasado para solventar una situación anómala, o bien personajes del pasado que aterrizan en el presente tras alterar una realidad que se había mantenido intacta durante milenios. En cualquier caso, y por muy fantástica que pueda resultar, la trama siempre tiene lugar en una realidad espacio-temporal acotada y «factible» dentro de los márgenes de la Tierra.

Este es, sin lugar a dudas, el planteamiento mayoritario de películas, series, videojuegos y otros formatos de la cultura de masas en nuestros días. Sin embargo, resulta llamativo el hecho de que en no pocos casos se reoriente la mirada y la arqueología aparezca como punto de enlace a mundos paralelos que tienen más que ver con el futuro que con el pasado. El cine de ciencia ficción, dadas las particularidades de su formato y de sus imaginarios, ha sido el principal impulsor de esta manera alternativa de entender la arqueología, en la que entran en escena viajes interestelares y civilizaciones alienígenas. 


\section{LA ARQUEOLOGÍA EN EL CINE DE CIENCIA FICCIÓN}

A la hora de valorar la percepción de la arqueología en la cultura de masas y, más concretamente, en el cine, no deja de ser sintomático que la mayoría de las películas de temática arqueológica puedan ser clasificadas como de tipo fantástico o de ciencia ficción, aunque en ambos casos se enmarcarían dentro de una etiqueta más amplia: la del género de aventuras. En cambio, son muy pocas las películas que ofrecen ya no solo una visión precisa sobre la profesión (Tejerizo, 2011; Vizcaíno Estevan, 2014: 22), una de cuyas excepciones sería The Body (2001), sino directamente una historia en la que no hagan acto de presencia los viajes en el tiempo, las odiseas en templos y pirámides y el enfrentamiento con seres fabulosos.

Dentro de ese mundo de ficción arqueológica, las producciones del género de la ciencia ficción han generado unos relatos diferenciados que rompen en parte con el esquema que domina en la cultura de masas a la hora de representar la arqueología. En ellas no existe un viaje en el tiempo, ya sea del presente al pasado o del pasado al presente, sino que se construyen unos escenarios en los que conviven pasado, presente y futuro. En concreto, se define un presente que está ambientado en el futuro pero conserva algunas cápsulas de pasado, como veremos más adelante.

Este cambio de perspectiva es importante puesto que resitúa el foco de atención temporal y, con él, plantea interesantes reflexiones sobre las maneras en que la sociedad occidental percibe el pasado y el futuro y sus implicaciones para el presente.

Asimismo, en estas películas el desplazamiento hacia lo exótico y lo desconocido no se produce dentro de la Tierra -o al menos no generalmente-, a diferencia de lo que ocurre con el cine más "clásico" del tipo Indiana Jones, sino que se desbordan sus límites y se proyectan hacia otros planetas y galaxias. Con este gesto, el cine de ciencia ficción arqueológica abre las puertas a la exoarqueología, una corriente que trata de encontrar evidencias de civilizaciones alienígenas tanto en la Tierra como en otros planetas y que, por tanto, se aleja de la disciplina científica (si bien en las últimas décadas se ha abierto el debate de la exoarqueología como estudio arqueológico de las huellas humanas en el espacio, esto es, el patrimonio espacial) (Campbell, 2004; Shanks, Platt y Rathje, 2004: 65ss; Schiffer, 2013).

A pesar de que el listado de películas en las que la arqueología se acomoda a las necesidades de la ciencia ficción es más extenso, en este trabajo hemos seleccionado por su representatividad cuatro ejemplos: Stargate (1994), El Quinto Elemento (1997), Alien versus Predator (2004) y Prometheus (2012) (Fig. 1). Todas ellas reiteran una serie de ideas que contribuyen a perfilar una 

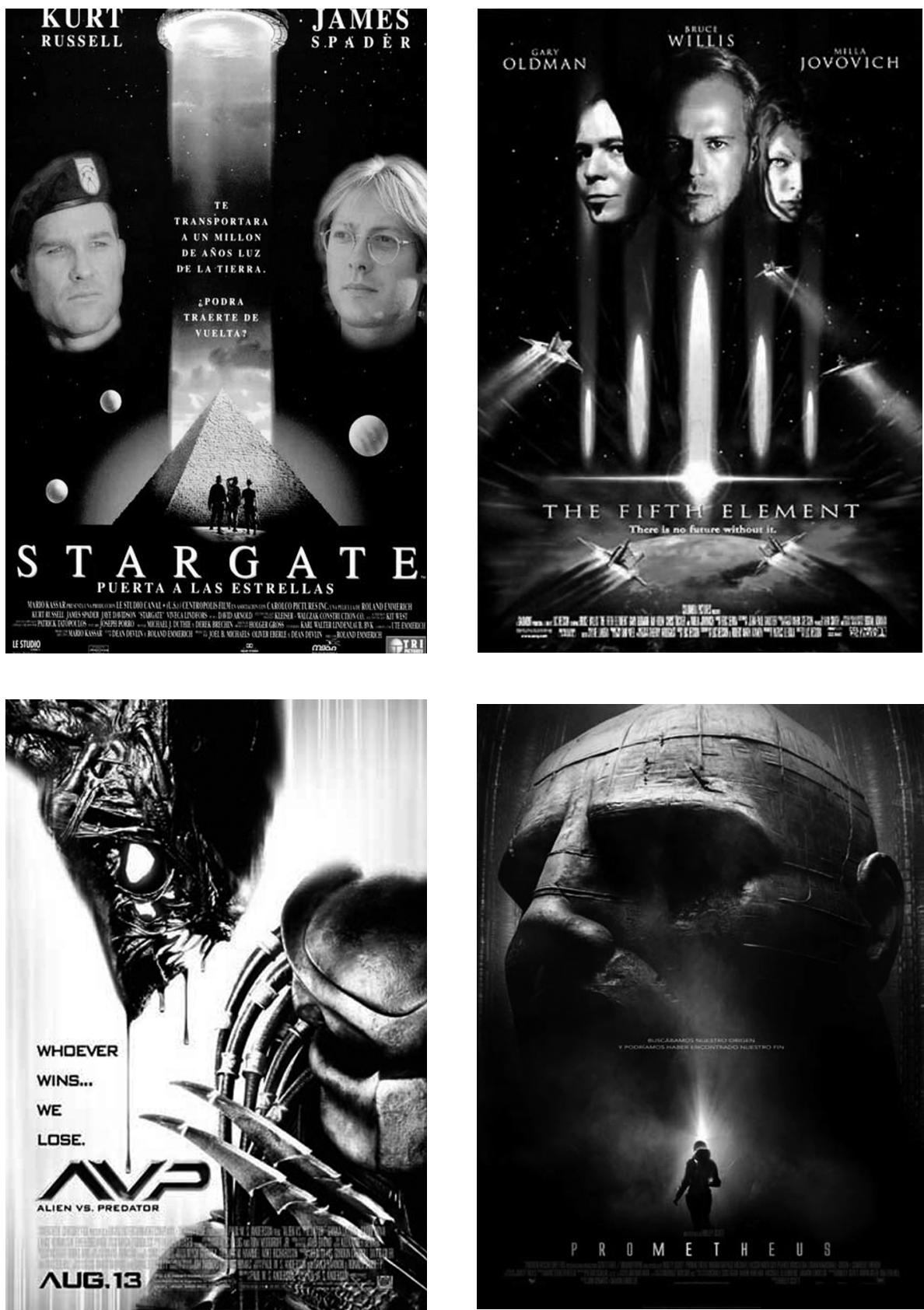

Fig. 1. Carteles de las películas analizadas: Stargate, El Quinto Elemento, Alien versus Predator y Prometheus. 
noción de arqueología desvinculada de lo terrenal, que busca proyectarse hacia realidades paralelas de clara inspiración futurista. No obstante, también existen notables diferencias de planteamiento, y por ejemplo El Quinto Elemento se distancia claramente de las otras tres producciones a la hora de situar la arqueología y su papel en la trama.

A continuación analizaremos las maneras de concebir y representar la arqueología en la muestra seleccionada y lo haremos de manera transversal a través de cuatro temas principales: la importancia de la cultura material, la función del arqueólogo, la trascendencia del viaje y las consecuencias del contacto alienígena.

\subsection{La materialidad como enigma}

Por más que las películas de ciencia ficción de tipo exoarqueológico construyan relatos y escenarios que divergen de los de las películas "clásicas" sobre arqueología, hay una circunstancia que no varía: la centralidad de la cultura material. Los restos arqueológicos funcionan, una vez más, como elemento catalizador del contacto con lo desconocido. Ahora bien, en estas películas lo desconocido no está representado por un pasado antiguo que espera paciente bajo el subsuelo a ser revivido, tanto literal (a través de personajes que vuelven a la vida) como metafóricamente (el conocimiento de ese pasado), sino por un presente alternativo de vocación futurista.

Vista de esta manera, la materialidad, más que una evidencia de las manifestaciones culturales de las civilizaciones antiguas, aparece como contenedor de una serie de mensajes cifrados legados por alienígenas que visitaron la Tierra cuando la humanidad todavía estaba sumida en un estadio de primitivismo. Dichos mensajes fueron encriptados y ocultados a la espera de que los humanos estuviesen en condiciones de interpretarlos. En las películas, ese futuro de madurez ya se ha hecho presente y la humanidad ha alcanzado un nivel intelectual y tecnológico suficientemente alto como para leer los mensajes, que no son sino hojas de ruta para llegar hasta quienes los crearon tiempo atrás.

Los restos arqueológicos que desencadenan la aventura en calidad de transmisores de mensajes adoptan, generalmente, la forma de objetos muebles más que de construcciones, si bien no es infrecuente la combinación de ambos. Esto se debe a que la aparición del objeto protagonista suele producirse en el contexto de una excavación o prospección arqueológica, en relación, pues, con otras estructuras y objetos. Pero la atención acaba centrándose en exclusiva en la pieza-fetiche.

Es el caso de la famosa puerta estelar de la película Stargate, un gran anillo fabricado con un mineral desconocido por los humanos, hallado en el transcurso 
de una excavación en Egipto en 1928 (Fig. 2). Dada su singularidad, la estructura es extraída y trasladada en un momento indeterminado a los Estados Unidos y custodiada bajo condiciones de máxima seguridad en la base militar de Creek Mountain, Colorado, donde permanece indescifrable hasta el presente en el que se ambienta la película, los años 90. En ella hay labrados una serie de símbolos que representan constelaciones, las cuales debidamente combinadas generan un agujero de gusano que conecta con la galaxia de donde proceden los alienígenas. Una invitación en toda regla que debía ser interpretada correctamente por una persona con amplios conocimientos sobre el mundo egipcio.

En El Quinto Elemento el protagonismo recae sobre un conjunto formado por cuatro piezas de piedra que se corresponden con los cuatro elementos (tierra, agua, aire y fuego) y una escultura que representa el quinto elemento. Del mismo modo que en Stargate, el hallazgo de estas piezas singulares está ambientado a principios del siglo XX, concretamente en 1914, que es la época dorada de las exploraciones arqueológicas europeas en el ámbito colonial. De nuevo es Egipto el escenario escogido, si bien en esta ocasión se trata de un templo perdido en el desierto, donde un mural de jeroglíficos a punto de ser descifrados por un arqueólogo sirve de antesala al sanctasanctórum en el que se encuentran los «elementos», que resultan ser un arma poderosísima para luchar contra el mal.

Por su parte, Alien versus Predator sitúa como centro de atención una pirámide sepultada bajo el hielo y la nieve de la Antártida. Se trata de una gran estructura detectada de manera casual por el empresario Weyland cuando uno de sus satélites prospecta la zona en busca de minerales. Intrigado por el hallazgo, del que solo tienen las evidencias identificadas por radar, consulta a distintos expertos, pero cada uno tiene una opinión distinta sobre el origen de la pirámide: azteca, camboyana, egipcia (Fig. 3). No en vano, acaban comprobando que la construcción integra características de las tres culturas y es, con probabilidad, la primera pirámide de la historia de la humanidad.

La idea de la conexión entre culturas pertenecientes a lugares y épocas muy distantes entre sí, que tendría su explicación en una supuesta raza alienígena como origen común, aparece también en Prometheus. Aquí el hallazgo que da pie al argumento de la película es diferente al resto, pues las pirámides y el mundo egipcio y mesoamericano son sustituidas por unas pinturas rupestres prehistóricas descubiertas en una cueva de Escocia. No obstante, pronto los protagonistas ponen en relación ese descubrimiento con otras representaciones muy similares halladas en otros puntos del planeta: estelas egipcias, mesopotámicas, mesoamericanas, etc. Todas ellas con una representación común: una serie de figuras humanas adorando a un ser de tamaño superior que envía unas 


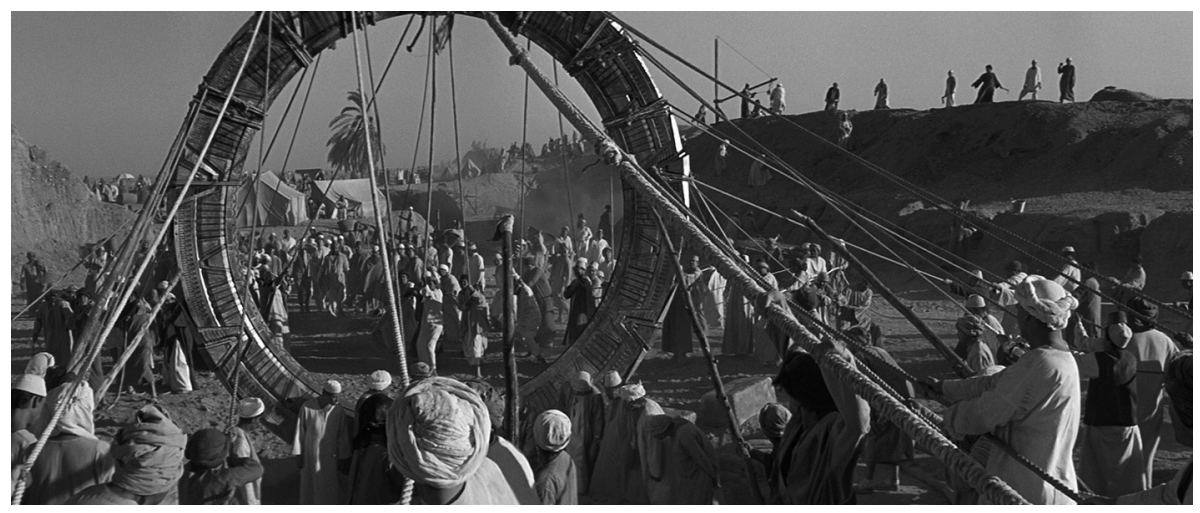

Fig. 2. El descubrimiento de la puerta estelar en una excavación arqueológica de 1928 en Stargate.

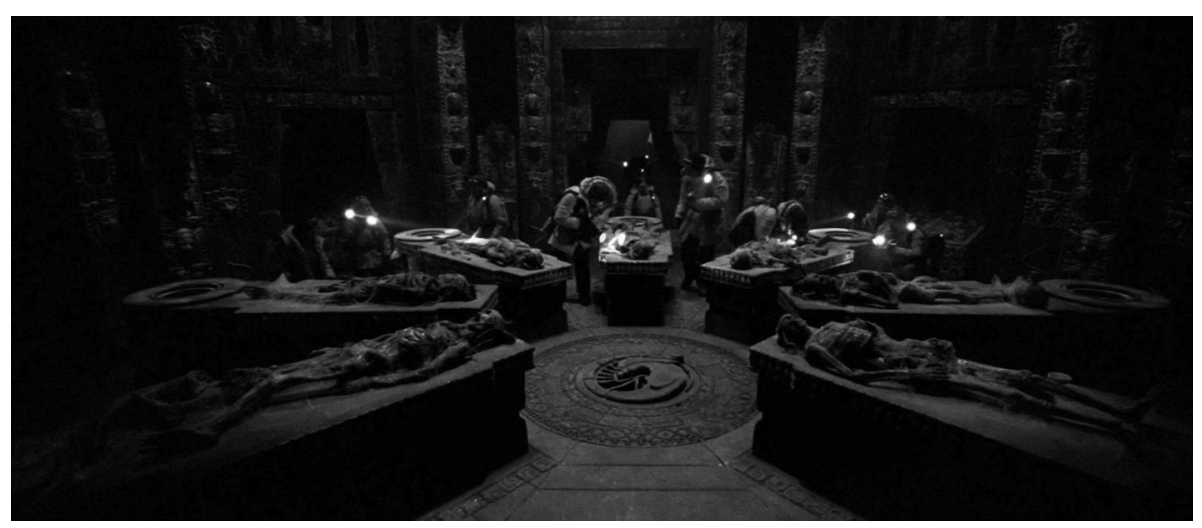

Fig. 3. La sala de sacrificios de la pirámide en Alien versus Predator, inspirada en el mundo mesoamericano. 
cápsulas hacia el cielo en una disposición particular. Se trata, en realidad, de la representación de una constelación que marca el camino hacia otro planeta, de un modo similar a Stargate.

En definitiva, estas películas participan de la antes mencionada fetichización de la cultura material, que se convierte en auténtica reliquia con valor por sí misma: es el mensaje que esta encapsula lo que verdaderamente importa y no hay necesidad de contextualización. Basta, a lo sumo, con fecharla y adscribirla culturalmente. Sin embargo, la capacidad de interpretar los mensajes cifrados no está al alcance del común de los mortales, sino que requieren de un conocimiento vasto y profundo. Es aquí donde entran en acción los arqueólogos, que a menudo son los verdaderos protagonistas de los largometrajes.

\subsection{El arqueólogo como intérprete y mediador}

En la introducción de este estudio hemos señalado que la representación de la figura del arqueólogo no cuenta, en el imaginario colectivo occidental, con una imagen homogénea. Es cierto que existe un arquetipo que se ha asentado con mayor fuerza gracias a la tradición de una cultura visual y narrativa muy potente: la del arqueólogo aventurero (Holtorf, 2007: 63ss). Ahora bien, este ideal, repetido hasta la saciedad en todo tipo de formatos, convive con otros arquetipos diferenciados, entre ellos el arqueólogo erudito y algo despistado, uno de cuyos exponentes más claros es el padre de Indiana Jones.

Las películas que estamos analizando muestran una predilección por este segundo arquetipo, aunque también se dan fórmulas híbridas. Lo que se destaca, por encima de todo, es la posesión de vastos conocimientos sobre pasado que permiten ir solventando los distintos enigmas que surgen a lo largo de la aventura y que conducen, finalmente, a una última pregunta de gran trascendencia para la cual no siempre hay respuesta. Así, frente a la figura de Indiana Jones y Lara Croft, a los que se les presupone inteligencia y conocimiento pero, sobre todo, habilidad física para hacer frente a todo tipo de peligros, los protagonistas de las cuatro películas analizadas son ante todo grandes conocedores del pasado.

No obstante, el tratamiento de estos personajes es distinto dependiendo de la época en la que se ambientan las películas. En los casos en los que el hallazgo arqueológico que desencadena la trama tiene lugar en el pasado reciente o en el presente -entiéndase aquí un presente "posible", es decir, un presente que no supera el momento real de producción del film-, la figura del arqueólogo tiende a responder a la imagen clásica del erudito que vive enfrascado en 
sus estudios y se muestra poco resolutivo en las situaciones de peligro. En este grupo encontraríamos al profesor que aparece en la escena inicial de El Quinto Elemento (Fig. 4), en el interior de un templo egipcio, tan concentrado en descifrar los jeroglíficos que aburre a su ayudante arqueólogo y apenas se percata de la llegada de una nave espacial y del desembarco de los Mondoshawan, una raza alienígena que busca proteger los "elementos".

Es también el caso del arqueólogo de Stargate, Daniel Jackson, un joven egiptólogo de los años 90 cuyas interpretaciones heterodoxas sobre la civilización egipcia le han granjeado el descrédito del mundo académico y le han llevado al borde mismo de la miseria debido a la falta de apoyo, situación que cambia inesperadamente cuando recibe la propuesta de Catherine Langford de participar en el proyecto Stargate.

También Sebastian de Rosa, el arqueólogo protagonista de Alien versus Predator, coincide con la idea de un arqueólogo apasionado por su trabajo pero muy incomprendido y con serios problemas económicos para llevar adelante sus proyectos, lo que le lleva a sumarse a la expedición para estudiar la misteriosa pirámide de la Antártida. Pero presenta una particularidad, y es que en él se da la doble vertiente erudito-héroe de acción de la que carecen los dos personajes anteriores.

En cambio, la ambientación de aventuras en el futuro, como la de Prometheus en el año 2089, da pie a construir la imagen del arqueólogo como un auténtico científico -en el sentido más "puro" del término- que combina conocimientos muy amplios sobre el pasado con el dominio de técnicas punteras y grandes habilidades para la supervivencia, lo cual probablemente no deba entenderse tanto como algo meritorio de la arqueología, sino como parte de las exigencias del guión, dado que se está recreando un futuro altamente tecnologizado. En este caso son Elizabeth Saw y Charlie Holloway, la pareja de arqueólogos de Prometheus (Fig. 5), que además de ser reconocidos especialistas en su campo -el resto de la tripulación, incluyendo científicos de otras disciplinas, se refieren a ellos como "doctores"-, manejan técnicas relacionadas con la medicina y la genética y se desenvuelven con soltura en contextos de acción.

A pesar de las diferencias, todos los personajes mencionados comparten una serie de rasgos comunes que los convierten en figuras indispensables -cuando no directamente en protagonistas- de las películas. La principal, ya mencionada, es su alto grado de conocimiento sobre el pasado, principalmente sobre las lenguas antiguas. En la mayoría de casos no son presentados solo como arqueólogos, sino también como lingüistas, lo cual remite a una concepción filológica de la arqueología muy característica de principios del siglo XX. Y tanto mejor cuanto más complejas sean esas lenguas, pues desde el punto de vista narrativo 


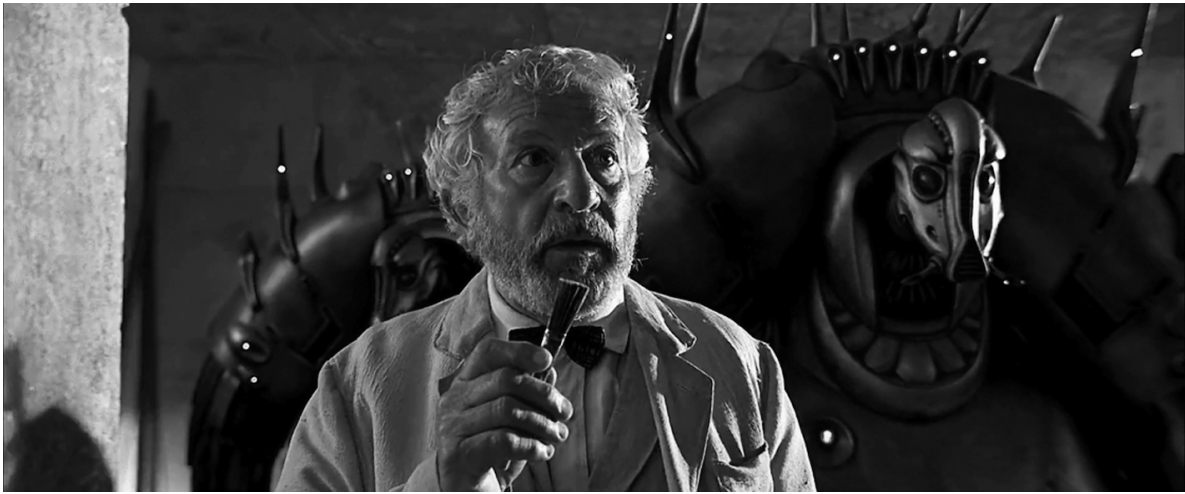

Fig. 4. El arquetipo del arqueólogo erudito ensimismado en El Quinto Elemento.

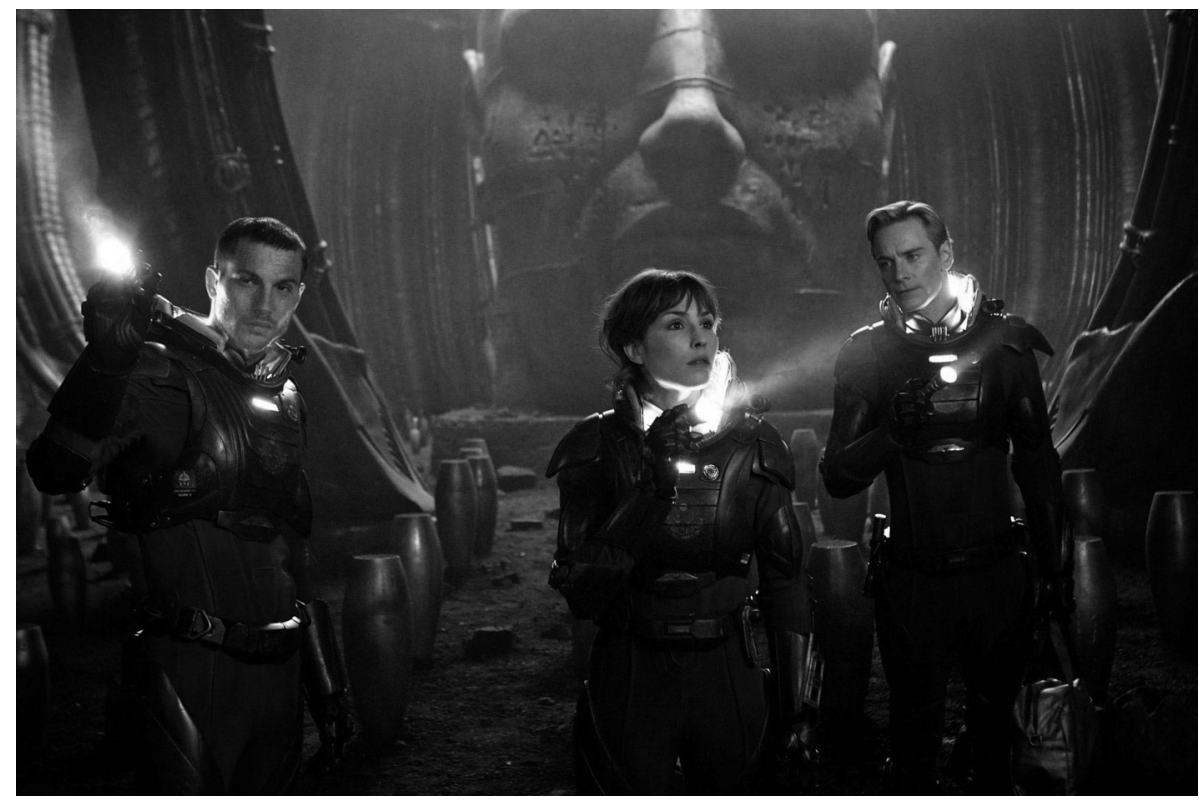

Fig. 5. A la izquierda, los arqueólogos Charlie Holloway y Elizabeth Saw en Prometheus. 
permiten distanciarse simbólicamente de nuestro sistema cultural, refuerzan el sentido enigmático y ponen en valor la exclusividad y el valor de quien conoce dichas lenguas.

Esto explicaría que en todas las películas analizadas los textos que deben ser descifrados para poder proseguir con la misión sean de tipo pictográfico o jeroglífico, de modo que resultan inaccesibles para la mayoría. Tan solo los arqueólogos pueden leer las pistas dejadas por los alienígenas e incluso llegar a comunicarse cara a cara con ellos, como ocurre en Stargate con las similitudes entre el egipcio que conoce Daniel Jackson y el que hablan los habitantes del nuevo planeta. Es también el caso de David, el androide de Prometheus, que durante el tiempo que dura el viaje hasta el planeta de destino, mientras los humanos son inducidos a un sueño permanente, aprende lenguas antiguas para tener recursos ante un hipotético encuentro con los extraterrestres. Es interesante señalar aquí que otras películas que no son de temática arqueológica también reproducen la idea del experto en lingüística como la persona más capacitada para mediar en caso de contacto alienígena. Un ejemplo evidente lo encontramos en el largometraje Arrival (2016) con la experta lingüista Louise Banks.

Es precisamente la habilidad para leer las pistas y comunicarse con las civilizaciones alienígenas la que determina que el éxito de la misión recaiga en manos de los arqueólogos. Ahora bien, no es extraño que la capacidad intelectual tenga el contrapunto de una dependencia respecto de otras figuras de la expedición, generalmente militares, pues los arqueólogos no siempre están en condición de manejar armas y defenderse de los peligros. Hasta tal punto es así que, en ocasiones, su curiosidad científica y la inconsciencia les lleva a poner en riesgo la seguridad del grupo, con el consiguiente rechazo por parte de algunos de sus componentes, incluyendo otros científicos. El ejemplo paradigmático es Daniel Jackson de Stargate, despreciado por los marines de la misión por mantenerlos más tiempo del deseado en un planeta hostil y peligroso. Solamente al final, cuando el arqueólogo ha demostrado su compromiso con la supervivencia del equipo y de la gente sometida por $\mathrm{Ra}$, consigue ganarse su respeto. También ocurre con Elizabeth Saw en Prometheus, tachada de fanática por los otros científicos debido a su obsesión por encontrar respuestas a preguntas que exceden los intereses particularistas de las distintas disciplinas.

\subsection{El viaje como iniciación}

Acceder a esas realidades paralelas en las que se pretende entrar en contacto con los alienígenas requiere de un necesario viaje que sirve como transición y frontera entre la realidad conocida y los escenarios incógnitos. 


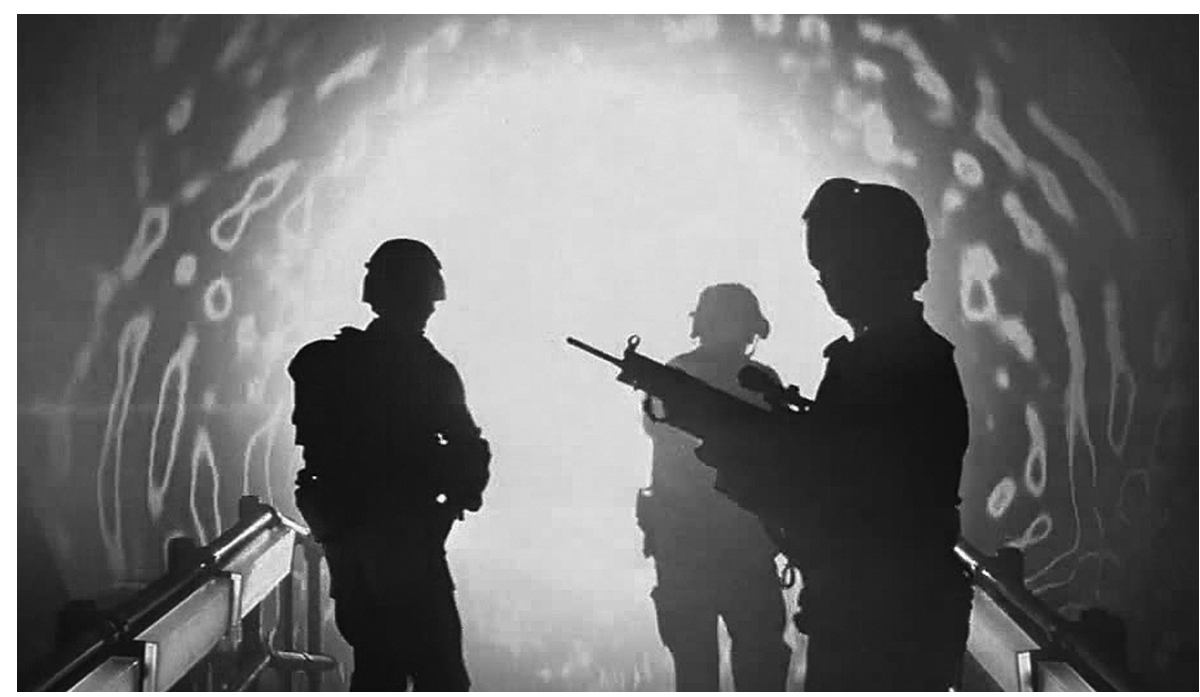

Fig. 6. Instantes previos al viaje interestelar por descomposición molecular en Stargate.

Existe un desplazamiento físico que es el que permite evocar la idea de aventura y de alejamiento de lo cotidiano. La manera más clara de representar esto es situar como destino final otros planetas y galaxias, tal y como ocurre en Stargate, El Quinto Elemento y Prometheus. Abandonar no solo el planeta Tierra, sino incluso nuestra galaxia, refuerza la idea de distanciamiento. En algunos casos el propio viaje resulta extremadamente largo, como en Prometheus, donde ni siquiera la nave espacial epónima, diseñada con tecnología punta, puede acortar los más de dos años de travesía, para lo cual se induce a todos los miembros de la misión -excepto al androide-a un prolongado letargo. En cambio, en Stargate los millones de quilómetros que separan nuestro mundo del lejanísimo planeta donde gobierna Ra son salvados en cuestión de segundos por el proceso de descomposición molecular que experimentan los protagonistas al traspasar la puerta estelar (Fig. 6). La diferencia subyace, obviamente, en que en el primer caso la tecnología es humana y en el segundo alienígena.

Pero el destino no tiene por qué estar necesariamente ubicado fuera de la Tierra. En Alien versus Predator, por ejemplo, la misteriosa pirámide que detectan los satélites se encuentra en nuestro planeta. Eso sí, no en cualquier lugar, sino en el más recóndito: la Antártida. Además de localizarse en una isla totalmente inhóspita, la pirámide está construida en una enorme cavidad subterránea. Esto 
último es clave, por cuanto lo subterráneo funciona como reflejo de lo desconocido (Holtorf, 2005: 16ss) y es un recurso compartido por las películas de ciencia ficción que estamos analizando, pero también por las más clásicas sobre arqueología. Recordemos, por ejemplo, que la base militar donde se custodia la puerta estelar en Stargate está en el interior de una montaña, y lo mismo ocurre con la nave donde se desarrolla la mayor parte de la historia de Prometheus.

De manera simultánea al desplazamiento físico se da también un viaje simbólico. Los miembros de las distintas expediciones constituyen un grupo privilegiado, seleccionado por su preparación -intelectual en unos casos, militar en otros- para participar de algo completamente nuevo y de consecuencias trascendentales para nuestro mundo. En Alien versus Predator, por ejemplo, una inscripción sirve de advertencia a los integrantes de la misión antes de adentrarse en la pirámide: "solo los elegidos pueden entrar".

En el caso de los arqueólogos, el viaje iniciático supone además una revolución epistémica por cuanto trastoca los esquemas de todo lo que se conocía y presuponía hasta el momento sobre la historia de la humanidad. Así, en Stargate las interpretaciones heterodoxas de Daniel Jackson sobre la civilización egipcia, tan denostadas por sus colegas de profesión por la falta de cientificidad, se tornan verídicas al embarcarse en la expedición. La propia Catherine Langford, benefactora del proyecto, se lo insinúa al conocerle, ofreciéndole una oferta que no podrá rechazar: “¿Quiere demostrar que sus teorías son ciertas? Esta es su oportunidad". A pesar de que antes del viaje ni tan solo él defiende una lectura alienígena e incluso rebate la posibilidad de que las inscripciones egipcias que se custodian en la base militar de Colorado tengan más de 10.000 años de antigüedad, el viaje a través de la puerta estelar le abre los ojos y le permite convertirse en el único arqueólogo que conoce la verdad sobre la civilización egipcia, que resulta ser mucho más antigua de lo que se creía y debe su esplendor al contacto con los alienígenas. Al ser consciente de lo que implica que haya vida egipcia en el otro extremo de la galaxia, Jackson afirma: "Lo sabía". Simbólicamente, el alejamiento de la lectura científica queda representado en la película al poco de aterrizar en el nuevo planeta, cuando los militares, molestos por la despreocupación del arqueólogo, arrojan su maleta de libros y estos caen rodando duna abajo, sin que él haga ningún esfuerzo por recuperarlos. Al fin y al cabo, esos libros parecen no tener ya validez tras haber descubierto la verdad sobre la civilización egipcia.

En un sentido muy similar, cuando Meredith Vickers, representante de la empresa Weyland en la exploración de Prometheus, contempla una especie de eco lumínico que proyecta el paso de unos alienígenas dos mil años atrás, piensa en voz alta: "Lo sabía". Es en ese preciso momento cuando es consciente 
de que la inicialmente descabellada hipótesis de los arqueólogos de que los restos arqueológicos aparecidos en distintos puntos del planeta hiciesen referencia a una misma civilización alienígena, es, en realidad, plausible.

Ahora bien, el viaje simbólico, que funciona como un viaje iniciático hacia un nivel de conciencia más elevado sobre la condición humana, no se da de la misma manera ni en el mismo nivel en todos los integrantes de la expedición. Llama la atención que frente a la visión más individualista que suele mostrarse sobre los arqueólogos en las películas de estilo indianajonesco, que a lo sumo se acompañan de personajes como la mujer que siempre está en apuros -puntualmente el hombre, como ocurre en Tomb Raider y en la serie Cazatesoros(Vizcaíno Estevan, 2014: 22) o los ayudantes indígenas -que cumplen a rajatabla el papel del "buen salvaje"-, en algunas de las producciones de ciencia ficción se ofrece una imagen mucho más diversa y modernizada: las misiones están compuestas por equipos multidisciplinares que incluyen, además de arqueólogos, a geólogos, ingenieros, bioquímicos, paleontólogos, astrofísicos y, por supuesto, a los militares responsables de la seguridad del grupo.

Pero, como señalábamos, no todos participan en igual medida de la trascendencia del viaje, de ahí que tampoco todos consigan sobrevivir a la misión. En los nuevos universos con los que se topan, la muerte no es solo cosa de supervivencia física, sino también de capacidad intelectual e incluso espiritual. No en vano, la mayoría de los "protectores" (los militares) acaban muriendo, excepto algún cargo superior que se salva porque encarna la humanidad y el sentido común (lo real) frente a las quimeras de los científicos. Estos, por su parte, tampoco sobreviven en su conjunto y no es infrecuente que determinadas disciplinas salgan mal paradas a causa de personajes estereotipados que evocan la "frialdad" de la ciencia, cuando no una supuesta inhumanidad. Un planteamiento que se puede poner en relación con algunas preconcepciones actuales sobre la ciencia, identificadas sobre todo a partir de los años 80 del siglo XX, a raíz de los debates éticos en torno a los límites del progreso científico (NietoGalán, 2011: 275ss), según las cuales la ciencia tiende a anteponer sus propios intereses investigadores -y también económicos-a los de la propia humanidad. Es el caso, por ejemplo, del uso de la ciencia para crear armas más mortíferas o para manipular genéticamente a los seres vivos.

Frente a esa visión casi desalmada de las ciencias más "puras", la arqueología suele mostrar una faceta mucho más amable, quizá por la percepción más humanista de la disciplina, muy condicionada por esos personajes simpáticos y aventureros perpetuados por los medios de comunicación (Ascherson, 2004; Carvajal et al., 2011). Existen casos verdaderamente ilustrativos a este respecto. Uno de los más evidentes es el personaje de Elizabeth Saw en Prometheus, quien no solamente resulta más cercana para el espectador que otros científicos 


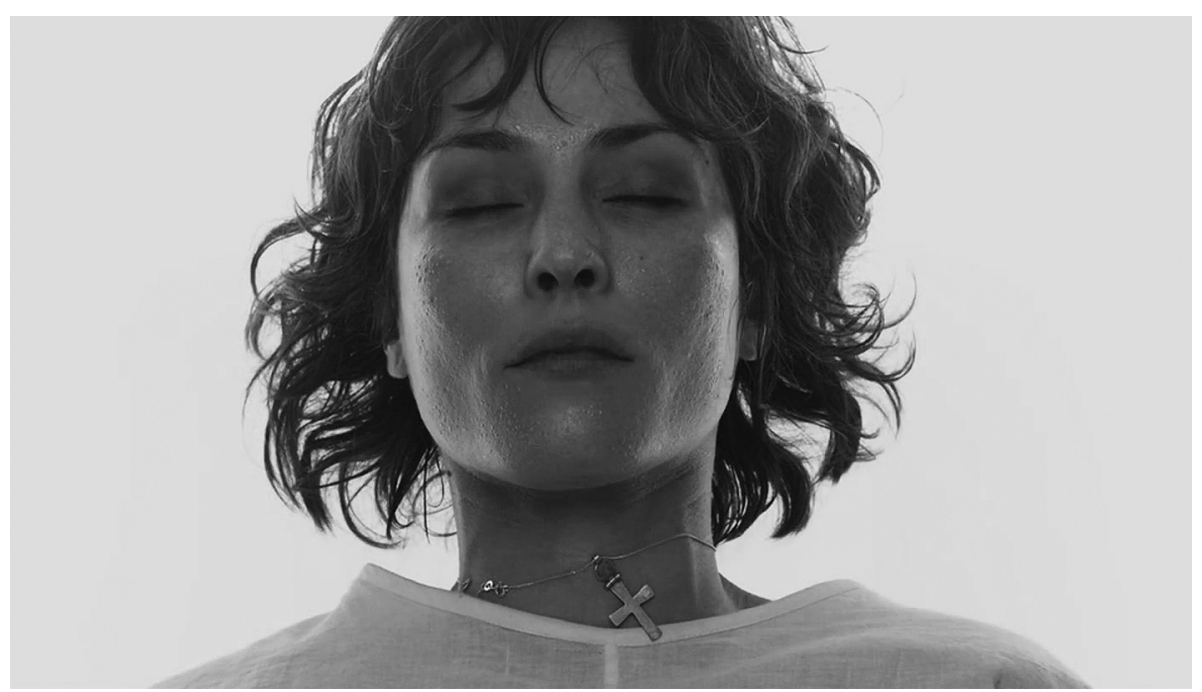

Fig. 7. Elizabeth Saw, arqueóloga en Prometheus, se debate entre la ciencia y la fe en los momentos críticos.

de la misión, sino que además aporta el componente espiritual, el de la fe, en el momento en que la ciencia se ha mostrado inoperante para dar respuesta a los grandes enigmas. En efecto, en ella la ciencia y la religión juegan una batalla y a pesar de que es su espíritu científico el que le hace buscar respuestas, las situaciones extremas le hacen encomendarse a Dios, de modo que es la fe y no la ciencia la que le permite sobrevivir y continuar adelante (Fig. 7). Sobre este conflicto entre ciencia y religión volveremos un poco más adelante.

En cualquier caso, en estas películas los arqueólogos suelen sobrevivir -hay alguna excepción, como Alien versus Predator, aunque en este film la ratio de muerte es tan alta que solamente logra salir con vida una persona, la técnica medioambiental- pues a ellos se les encomienda la misión de interpretar los mensajes y, llegado el caso, de comunicarse con los alienígenas.

\subsection{El encuentro con los alienígenas como catarsis}

Los nuevos mundos a los que arriban las expediciones son representados como auténticos "países extraños" (Lowenthal, 1998) donde lo conocido deviene incierto - pensemos en las tres lunas del planeta de Ra en Stargate- y 
donde la atmósfera se enrarece, en ocasiones hasta el punto de resultar tóxica, como sucede en Prometheus.

Por norma general se construyen escenarios hostiles de condiciones extremas que ayudan a incrementar la sensación de otredad: desiertos (de arena, roca o hielo), presencia mínima de seres vivos y peligros difíciles de identificar. A esto se añade la incursión a grutas y galerías subterráneas que simbolizan lo ignoto. Es precisamente ahí donde se produce el encuentro con los alienígenas.

El primer contacto no suele ser directo. Hay un proceso previo de asimilación a través de evidencias de la cultura material alienígena, en especial de estructuras arquitectónicas monumentales, a veces descomunales. Estas construcciones combinan una pátina de futurismo (exhibición de un híper desarrollo tecnológico, formas onduladas frente a rectilíneas, acabados metálicos) con referentes iconográficos extraídos del pasado. En esta fórmula híbrida hay una preferencia por la iconografía de las culturas que resultan más fascinantes para el gran público, de ahí la reiteración de símbolos y elementos egipcios reproducidos de manera literal o actualizados.

Así, en Stargate la llegada al nuevo planeta es de primeras como un viaje al Egipto de los faraones. Más allá del desplazamiento espacio-temporal, nada allí resulta sorprendente en exceso, pues tanto el interior del templo como el obelisco le son familiares a Daniel Jackson por los paralelos arqueológicos. Es al salir al exterior y descubrir que hay tres lunas en el cielo cuando la cosa comienza a cambiar. A partir de ese momento todo será una sorprendente mixtura de referentes reconocibles, como las propias gentes del desierto y sus poblados, la estética egipcia o la lengua, y desconocidos, entre ellos algunos animales, la alta tecnología y el dios $\mathrm{Ra}$, que resulta ser el único superviviente de una raza alienígena desaparecida (Fig. 8).

También en Alien versus Predator ocurre algo parecido, pues al acceder a las profundidades de la Antártida se topan con una gran pirámide escalonada que recuerda a las del mundo azteca, pero con añadidos egipcios y camboyanos. Una trilogía, por cierto, nada casual, pues se trata de tres de los principales focos de interés para los seguidores de la pseudoarqueología. En este film se juega, además, con un recurso muy habitual de las películas de aventuras de inspiración arqueológica: la pirámide-laberinto cuajada de galerías, cámaras secretas y trampas, cuya estructura se va reconfigurando a medida que se accionan palancas y falsas baldosas. Se trata de un mito, el de la pirámide-laberinto, construido ya durante la Antigüedad para ahuyentar a los saqueadores de tumbas, que ha sido tradicionalmente alimentado por los relatos de las exploraciones a tierras egipcias -incluyendo el celebérrimo descubrimiento de 


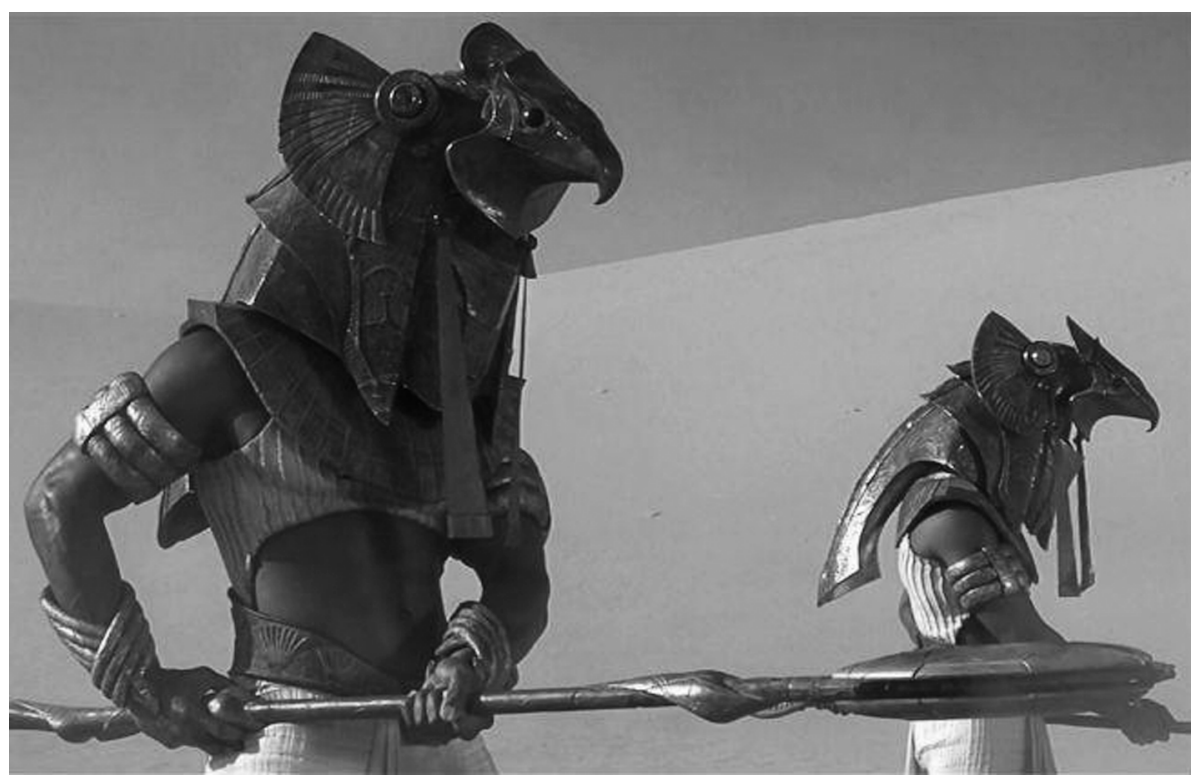

Fig. 8. Los soldados de Ra en Stargate, en los que se combina la estética egipcia con el híper desarrollo tecnológico.

la tumba de Tutankamón por Howard Carter en los años 20 y la supuesta maldición del faraón-y, más recientemente, por películas, videojuegos, documentales, novelas y series de televisión (McGeough, 2006). Es, en definitiva, la apelación a la pirámide (en cualquiera de sus adscripciones culturales) como lugar incierto y peligroso. De ahí que la protagonista de Alien versus predator, tras escapar al primer encuentro con los Aliens, responda con ironía al desconcertado arqueólogo: "Tú eres el experto en pirámides", insinuando que dentro de una pirámide puede pasar de todo.

Por su parte, en Prometheus lo que a priori parece ser una compleja red de túneles subterráneos tallados en la roca, con relieves e inscripciones hechas con signos antiguos pero de estética futurista, acaba siendo una inmensa nave espacial varada.

Estos escenarios inhóspitos sirven de antesala al encuentro con los alienígenas, los mismos que habían viajado milenios atrás a la Tierra para crear la civilización y después marcharse, no sin antes haber dejado una serie de pistas para que los humanos las interpretasen. Es, de alguna manera, el reencuentro cara a cara con los creadores, que encarnan la unión entre el pasado y el futuro. 
Es más, en algunas de estas películas los alienígenas son denominados "ingenieros" o "creadores" y se les atribuye una carga genética idéntica a la de los humanos. Así ocurre en Prometheus y, aunque con una lógica distinta, también en El Quinto Elemento. Eso sí, la fisionomía es variable. Desde Ra y sus secuaces de aspecto humano en Stargate, pasando por los Aliens y Predators y los humanoides de gran formato de Prometheus, hasta llegar a los Mondoshawan de El Quinto Elemento (Fig. 9), existe una amplia mitología alienígena, que en el caso de Stargate se enriquece todavía más con la adaptación del film a televisión a través de la aclamada serie de televisión Stargate SG-1 (1997-2007).

El fin último que mueve a los humanos a contactar con estas civilizaciones alienígenas es encontrar la respuesta a algunos interrogantes de gran trascendencia. ¿Quiénes son los creadores de la humanidad? ¿Por qué viajaron a la Tierra? ¿Qué motivó su marcha? ¿Y qué pretenden alentando el reencuentro? No obstante, ni los creadores resultan ser tan receptivos como esperaban los humanos, ni el descubrimiento de la verdad satisface sus anhelos. Más bien al contrario. Exceptuando a los Mondoshawan de El Quinto Elemento, que son los únicos alienígenas filántropos, en el resto de películas tienen planes nefastos para la humanidad: en Stargate Ra, después de haber esclavizado a miles de personas, pretende detonar una bomba de destrucción masiva en la Tierra y asevera: "Yo fundé vuestra civilización y seré yo quien la destruya". En la misma línea, los alienígenas de Prometheus estaban diseñando un arma letal para enviarla contra la humanidad, cuando su propio experimento se volvió contra ellos. Y en Alien versus Predator los humanos son utilizados de manera sistemática y a lo largo de milenios como incubadoras para criar las larvas de Aliens que serán cazadas por los Predators en una especie de rito de iniciación en el interior de la pirámide (Fig. 10).

Dar respuesta a preguntas importantes acaba siendo, pues, un episodio traumático para las distintas expediciones. Ahora bien, el desenlace de las películas introduce matices y juicios de valor dependiendo de cada personaje tipo y de los propósitos que subyacen en cada uno de ellos. Tanto en Prometheus como en Alien versus Predator se descubre que los promotores de las exploraciones se habían movido por intereses personales y no científicos: en un caso la búsqueda de la inmortalidad -no es casual que la nave espacial en la que viajan se llame Prometheus, el personaje de la mitología griega que quiso equiparar a dioses y humanos y fue castigado por ello- y en otro la fama y el reconocimiento. Es decir, buscan hacer historia a título individual, pero ambos fracasarán por su ambición. El fracaso queda bien atestiguado en la figura de Weyland, el promotor en Prometheus, quien justo antes de morir a manos de un alienígena afirma: "No hay nada". 


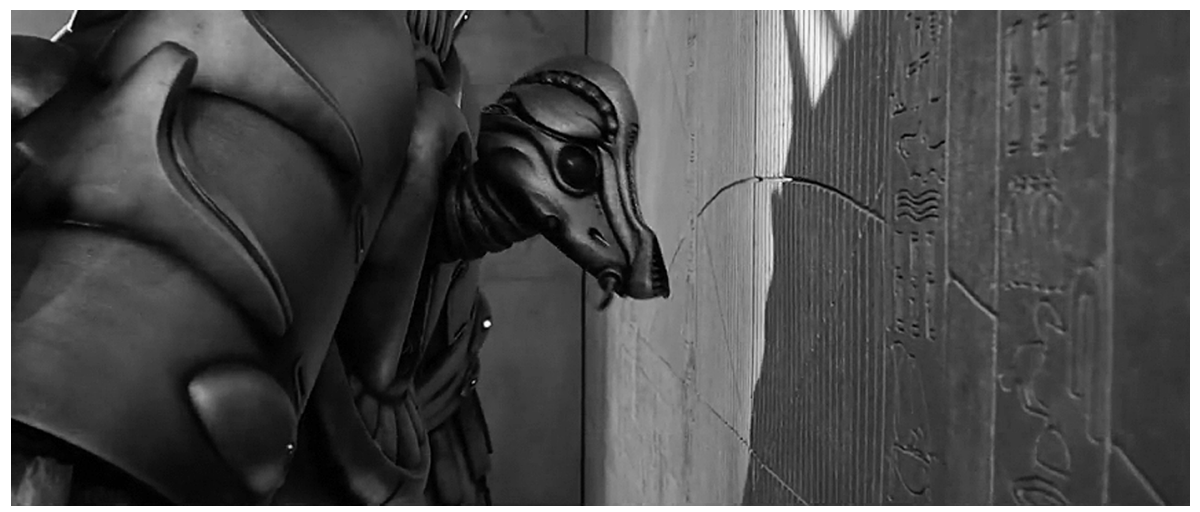

Fig. 9. Los Mondoshawan de El Quinto Elemento en el momento en que regresan a la Tierra para salvaguardar los "elementos".

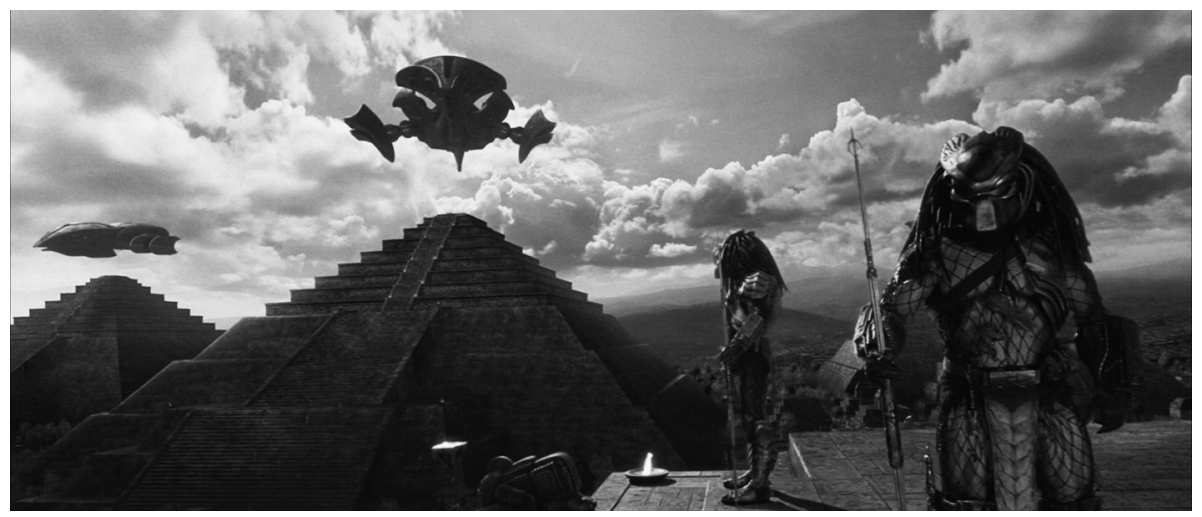

Fig. 10. Los Aliens preparados para los ritos de iniciación en Alien versus Predator. 
En cambio, los arqueólogos, a pesar de la frustración, perseveran en sus propósitos, con la diferencia de que a ellos no les mueve el interés exclusivamente personal y económico sino el conocimiento sobre la humanidad. Así, en la última película mencionada, Elizabeth Saw decide emprender como única superviviente un nuevo viaje en busca de respuestas, desoyendo la propuesta del androide de regresar a la Tierra, pues ella sí es humana y quiere conocer sus orígenes. Por su parte, Daniel Jackson, de Stargate, opta por quedarse en el nuevo mundo y cumplir su sueño: vivir en su propio objeto de estudio, el pasado, para conocerse mejor a sí mismo y a la humanidad.

\section{3. ¿POR QUÉ LA ARQUEOLOGÍA?}

Llegados a este punto conviene preguntarse: ¿qué hace que en el mundo de la ciencia-ficción la arqueología sea percibida como un efectivo enlace argumental a mundos paralelos?

Aquí hay que tener en cuenta el poso y el peso de las teorías especulativas de la llamada pseudoarqueología (Peque Martínez, 2013), en la que se incluye la propia exoarqueología. Según esta corriente, los importantes logros técnicos de determinadas civilizaciones antiguas y la existencia de manifestaciones culturales similares en puntos del planeta muy alejados y desconectados entre sí -como por ejemplo las pirámides-, estaría poniendo en evidencia el contacto de algunas sociedades humanas con alienígenas de cultura superior.

A pesar de que la pseudoarqueología cuenta con pocos adeptos en el ámbito científico - de hecho es una etiqueta utilizada desde la disciplina para delimitar interpretaciones poco rigurosas-, sus propuestas tienen mucho tirón en la sociedad occidental. Es más, existen personajes de gran impacto mediático que son claros defensores de estos posicionamientos, como Erich von Däniken a una escala internacional o el propio Iker Jiménez, presentador de Cuarto Milenio, en el caso español. Lo cierto es que estas lecturas alternativas del pasado están muy presentes en los productos de la cultura de masas, incluyendo revistas, documentales y libros. Sin ir más lejos, las películas que hemos analizado hacen continuos guiños a la pseudoarqueología y convierten al espectador en cómplice de ella recurriendo a personajes incomprendidos que acaban demostrando la verdadera realidad.

Estas interpretaciones pseudoarqueológicas se alimentan de una serie de presunciones sobre el pasado y la arqueología que están bien asentadas en nuestro imaginario colectivo, y que son distorsionadas hasta el punto de amoldarlas a sus intereses. Quizás la más significativa de todas ellas sea la concepción de la historia como un recorrido de progreso continuo e imparable, en el que lo 
más antiguo es siempre lo más atrasado y lo más reciente lo más avanzado (Wulff, 2002).

Esta idea de progreso, fundamentada en los méritos tecnológicos, desemboca en una suerte de condescendencia histórica -aquello de "¿cómo podían hacer algo así con los medios que tenían?". Es decir, se pone en entredicho que hace miles de años se pudieran alcanzar cotas de desarrollo tecnológico verdaderamente elevadas, lo cual lleva, en algunos casos, a buscar explicaciones alternativas. Como es de esperar, las principales afectadas por este tipo de preconcepciones son las civilizaciones que han legado las evidencias arqueológicas más sorprendentes, como la egipcia y algunas de las mesoamericanas y del sureste asiático. No es casual, además, que este posicionamiento se haya planteado mayoritariamente para civilizaciones ubicadas en territorios que a ojos occidentales encarnan lo diferente, lo exótico y hasta cierto punto lo salvaje. ¿Acaso alguien pone en entredicho la autoría humana de las obras de ingeniería romanas? Al contrario, se entienden como el germen de la cultura occidental, concretamente de la europea. En cambio, se cuestiona que países considerados -siempre desde la perspectiva occidental-subdesarrollados, cuenten con un pasado tan meritorio.

Otra de las presunciones que avivan el fuego de la pseudoarqueología es la fascinación y la maleabilidad del pasado. El pasado es, siguiendo la famosa expresión del geógrafo David Lowenthal (1998), un "país extraño" sobre el que no existen certezas, sobre todo cuando se trata de periodos muy antiguos para los que las fuentes de información son más limitadas. La falta de certezas es un auténtico revulsivo para las fabulaciones y abre la veda a la creación de auténticos mundos imaginados que se alejan de la realidad empírica, al tiempo que permiten distanciarse de las preocupaciones y la racionalidad del presente.

Esto no es ninguna novedad, pues las sociedades tradicionales han interpretado los restos arqueológicos de su entorno de acuerdo con sus propios universos culturales (Gazin-Schwartz y Holtorf, 2011), proponiendo lecturas que la ciencia ha tachado después de fantasiosas. De hecho, la fabulación del pasado ha sido una constante hasta el presente, incluso en convivencia con el surgimiento y consolidación de las disciplinas científicas encargadas de su estudio. Conviene no olvidar, en este sentido, el efecto que tuvo el Romanticismo en la idealización de las narraciones históricas y arqueológicas (Closa Farrés, 1993). Buena parte de las expediciones coloniales en busca de tesoros arqueológicos tuvieron mucho de relato fantástico y lo hicieron a través de la descripción de escenarios y personajes exóticos que se contraponían a lo conocido, es decir, a lo civilizado.

A pesar de que en la actualidad el discurso científico llega a buena parte de la sociedad a través de formatos muy diversos, lo hace en coexistencia -a menudo conflictiva- con discursos que distan de ajustarse a lo científicamente 
correcto pero que, sin embargo, apelan de manera muy efectiva al componente emocional, una de las principales razones de su éxito (Holtorf, 2007). Así, en cierta medida lo que han hecho y hacen las películas de arqueología de ciencia-ficción no es sino actualizar las narraciones decimonónicas y adaptarlas a la realidad de los siglos XX y XXI, donde lo exótico y lo desconocido pasa a ser lo alienígena y la tecnología híper desarrollada.

Finalmente, en la base de la proliferación de las interpretaciones pseudoarqueológicas está la asociación de la arqueología con lo desconocido. El medio por antonomasia del trabajo arqueológico es el subsuelo -a pesar, una vez más, de que la realidad de la profesión sea más diversa-, que al ser una realidad ajena remite a la idea de lo oculto, lo desconocido e incluso lo peligroso. De este modo, la arqueología se convierte en la herramienta para acceder a realidades desconocidas. En el relato arqueológico clásico esas realidades desconocidas están representadas por templos y tumbas subterráneas -en la inmensa mayoría de películas de tipo indianajonesco la acción se desarrolla en espacios subterráneos- y en la ciencia ficción se plasma a través de planetas desconocidos o en proceso de exploración, pues la Tierra se ha quedado pequeña y lo exótico, tan inherente a lo arqueológico, lo encarnan otras realidades.

\section{REFLEXIONES FINALES}

Parece evidente que el cine de ciencia ficción ha encontrado en la arqueología un referente a través del cual evocar una serie de ideas compartidas que encajan con algunos de los rasgos más característicos de este género (la aventura, el contacto con lo desconocido, el viaje iniciático) y, además, ha permitido dotarlo de recursos estilístico únicos (cultura material singular, referentes iconográficos, escenarios posibles). En este sentido, las películas de ciencia ficción de temática exoarqueológica no hacen sino reproducir un relato clásico, equiparable al de otras películas y otros formatos más tradicionales con presencia de arqueología, pero revistiéndolo de una estética y unos recursos de inspiración futurista.

Pero, al mismo tiempo, el uso de la arqueología en la ciencia ficción invita a reflexionar sobre cuestiones filosóficas de mayor calado que aparecen recogidas en este tipo de películas a través de la intervención de los arqueólogos. Una de ellas es el conflicto ciencia versus religión, que se plantea cuando la ciencia no es capaz de dar respuesta a algunas preguntas esenciales para la humanidad. Ante el fracaso y el sentimiento de desamparo se apela a lo más primario, esto es, a lo emotivo y lo espiritual, y curiosamente en algunas de estas películas esa mayor humanidad la representa la arqueología frente a otras cien- 
cias más "puras". Esto se hace en detrimento de una consideración verdaderamente científica de la arqueología, donde parece primar más lo que se quiere creer que lo que se puede demostrar. Al fin y al cabo, cuando se trata de entrar en contacto con el pasado, lo real y lo imaginario se entremezclan.

La otra reflexión clave que se desprende es la percepción distópica del futuro. Frente a un pasado casi siempre idealizado - pensemos en todas las películas con arqueólogos que viajan a un pasado épico y dulcificado-, el futuro se presenta incierto, oscuro e incluso catastrófico. Las respuestas no son siempre las esperadas y los humanos descubren que estaban al borde de la destrucción a manos de los alienígenas, lo cual les hace replantearse cuestiones sobre su propia naturaleza y su papel en el universo. Es más, en estas películas se tiende a visibilizar la insignificancia de los humanos en comparación con especies alienígenas mucho más desarrolladas y poderosas, frente a las cuales no hay nada que hacer. Y es que, al final, el verdadero "país extraño" resulta ser el futuro.

De un modo u otro, el recurso a la arqueología en las películas de ciencia ficción introduce la variable de la temporalidad y permite, a través de ella, poner sobre la mesa preocupaciones tan trascedentes como el de dónde venimos, dónde estamos y hacia dónde nos dirigimos. Y lo hace desde un posicionamiento catastrofista, en una suerte de crítica a las ambiciones de los humanos del presente que contrasta con la bondad e ingenuidad que se presupone a las sociedades del pasado, quienes, de acuerdo con esa lectura, serían menos ambiciosas pero más felices. En definitiva, la arqueología sirve como pretexto para hilvanar pasados y presentes y especular, partiendo de la experiencia histórica, sobre futuros posibles.

\section{FILMOGRAFÍA}

Anderson, P. (2004): Alien versus Predator, 20th Century-Fox Film / Brandywine Productions.

Besson, L. (1997): El Quinto Elemento, Gaumont.

Emmerich, R. (1994): Stargate: puerta a las estrellas, Carolco Pictures / Canal+ / Centropolis Film Productions.

Scott, R. (2012): Prometheus, 20th Century Fox / Scott Free Productions / Dune Entertainment / Brandywine Productions. 


\section{BIBLIOGRAFÍA}

ASCHERSON, N. (2004): “Archaeology and the British media”, en: Merriman, N. (Ed.), Public Archaeology, Londres, Routledge, 145-158.

BURCH, J. (2007): La patrimonialització de la materialitat etrusca a la Toscana, Girona, Universitat de Girona.

CAMPBELL, J. B. (2004): "The potential for Archaeology within and beyond the Habitable Zones (HZ) of the Milky Way", Bioastronomy 2002: Life Among the Stars (R. P. Norris y F. H. Stootman eds.), Proceedings of the International Astronomical Union, vol. 213, 505-510.

CARVAJAL, A.; HERNANDO, C.; SOTO, M. de los R.; TEJERIZO, C. (2011): “El síndrome de Indiana Jones. La imagen social del arqueólogo", Estrat Crític, 5 (3), 38-49.

CLOSA FARRÉS, J. (1993): “La imaginación absorta: la visión romántica de los descubrimientos arqueológicos en Roma”, Romanticismo y fin de siglo. Actas del Simposium sobre Romanticismo y Fin de Siglo (Palma de Mallorca, julio de 1990), Barcelona, Promociones y Publicaciones Universitarias, 78-117.

DÍAZ-ANDREU, M. (1995): “Archaeology and Nationalism in Spain”, en: Kohl, P. L. y Fawcett, C. (Eds.), Nationalism, politics and the practice of Archaeology, Cambridge, Cambridge University Press, 39-56.

FERNÁNDEZ MARTÍNEZ, V. M. (2011): “Arqueología y hegemonía: la contribución al pensamiento conservador español entre los siglos XIX y XX”, História, teoria e método da arqueologia. Actas do IV Congreso da arqueologia peninsular (Bicho, N. F. ed.), Faro, Universidade do Algarve, 281- 290.

GAZIN-SCHWARTZ, A., HOLTORF, C. (2011): Archaeology and folklore, Londres y Nueva York, Routledge.

HALL, M. A. (2004): "Romancing the stones: Archaeology in popular cinema", European Journal of Archaeology, 7(2), 159-176.

HOLTORF, C. (2005): From Stonehenge to Las Vegas. Archaeology as popular culture, Walnut Creek CA, Altamira Press.

LOWENTHAL, D. (1998): El pasado es un país extraño, Madrid, Akal.

McGEOUGH, K. (2006): "Heroes, Mummies and Treasure: Near Eastern Archaeology in the Movies", Near Eastern Archaeology, 69(3-4), 174-185.

MORA, G. (2015): “Arqueología y coleccionismo en la España de finales del siglo XIX y principios del XX", Museos y Antigüedades. El coleccionismo europeo a finales del siglo XIX. Actas del Encuentro Internacional Museo Cerralbo (Madrid, septiembre de 2013), Madrid, Ministerio de Educación, Cultura y Deport, 8-28.

NIETO-GALÁN, A. (2011): Los públicos de la ciencia. Expertos y profanos a través de la historia, Madrid, Marcial Pons.

PEQUE MARTÍNEZ, J. M. (2013): “Alternando con la 'arqueología alternativa””, en: Almansa, J., Arqueología Pública en España, Madrid, JAS Arqueología, 37-53. 
RODRÍGUEZ TEMIÑO, I. (2015): “Coleccionismo y expolio arqueológico: los comienzos de una relación problemática", Cuadernos de prehistoria y arqueología de la Universidad de Granada, 25, 211-256.

RUIZ ZAPATERO, G. (2012): "Presencia social de la arqueología y percepción pública del pasado", en Ferrer García, C. y Vives-Ferrándiz, J (Eds.), Construcciones y usos del pasado. Patrimonio arqueológico, territorio y museo, València, Diputació de València, 31-73.

TEJERIZO, C. (2011): “Arqueología y cine: distorsiones de una ciencia y una profesión”, El Futuro del Pasado, 2, 389-406.

SCHIFFER, M. B. (2013): “Archaeology of the Space Age”, en: Schiffer, M. B., The Archaeology of Science. Studying the creation of useful knowledge, Cham, Springer, 163-183.

SHANKS, M., PLATT, D., RATHJE, L. (2004): “The Perfume of Garbage: Modernity and the Archaeological", Modernism = Modernity, 11(1), 61-84.

VIZCAÍNO ESTEVAN, T. (2013): “Arqueología y sociedad: entre el idilio y la incomprensión”, en: Almansa, J., Arqueología Pública en España, Madrid, JAS Arqueología, 15-36.

VIZCAÍNO ESTEVAN, T. (2014): "El mirall de Lara Croft: arqueòlogues en un món de ficció”, en Vizcaíno, T., Machause, S., Albelda, V. y Real, C. (Eds.), Desmuntant Lara Croft. Dones, Arqueologia i Universitat. SAGVNTVM- PLAV, Extra 15, 17-24.

WULFF, F. (2002): "La Antigüedad en España en el siglo XIX", Arqueología fin de siglo. La arqueología española de la segunda mitad del siglo XIX. I Reunión Andaluza de Historiografía Arqueológica (Deames, M. B. y Beltrán Fortes, J., eds.), Sevilla, Universidad de Sevilla, 119-155. 